\title{
Ovalocyte Count
}

National Cancer Institute

\section{Source}

National Cancer Institute. Ovalocyte Count. NCI Thesaurus. Code C142287.

The determination of the amount of ovalocytes present in a sample. 